\title{
High skeletal muscle mass is associated with increased serum 25(OH)D levels in elderly
}

\author{
Verawati Sudarma* and Lukman Halim*
}

\section{ABSTRACT}

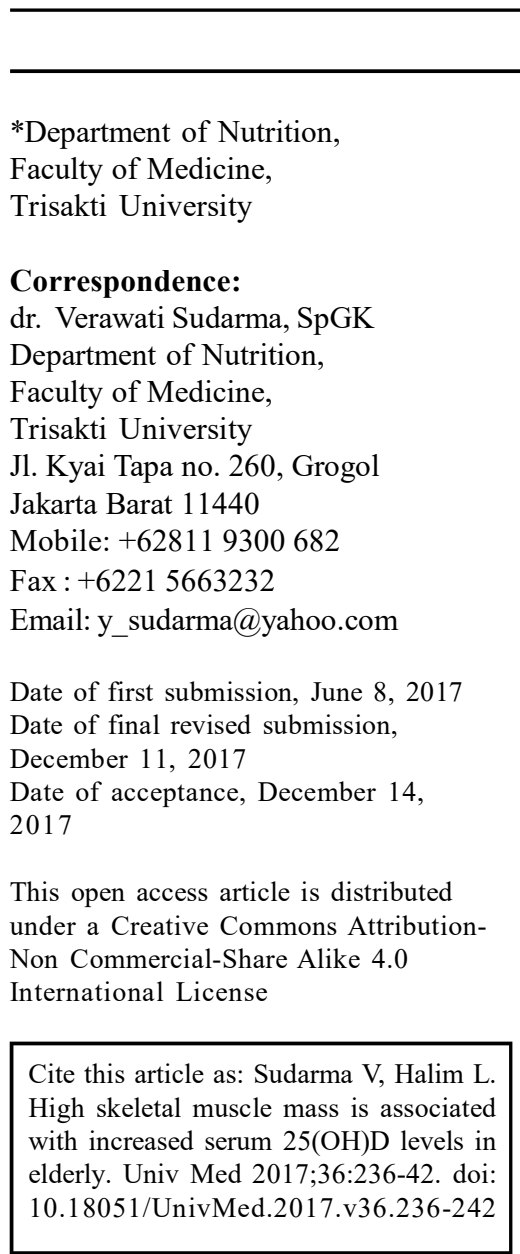

*Department of Nutrition Faculty of Medicine,

\section{Correspondence:}

dr. Verawati Sudarma, SpGK

Department of Nutrition,

Jl. Kyai Tapa no. 260, Grogo

Jakarta Barat 11440

Mobile: +628119300682

Fax : +62215663232

2017

under a Creative Commons Atribution-

Non Commercial-Share Alike 4.0

International License

Cite this article as: Sudarma V, Halim L. High skeletal muscle mass is associated elderly. Univ Med 2017;36:236-42. doi $10.18051 /$ UnivMed.2017.v36.236-242

\begin{abstract}
BACKGROUND
Low vitamin D has been associated with various health problems. Aging influences body composition, especially body fat and fat-free mass. Anthropometric measurements, such as body weight (BW), body mass index (BMI), body fat (BF), skeletal muscle mass (SMM), waist circumference (WC) and the waist-height ratio (WHtR) represent body composition which many studies proposed will influence serum vitamin $\mathrm{D}$ [25(OH)D]. The objective of the present study was to determine which anthropometric measurements were determinants of $25(\mathrm{OH}) \mathrm{D}$ levels in elderly.
\end{abstract}

\section{METHODS}

A cross-sectional study was conducted involving 126 elderly ( $>60$ years old) men and women at Pusat Santunan Dalam Keluarga (PUSAKA) Central Jakarta centers. Anthropometric measurements [body mass index (BMI), skeletal muscle mass (SMM), body fat (BF), and waist circumference (WC)] were determined by bioelectrical impedance analysis using the Omron body composition monitor with scales (HBF-375, Omron, Japan). Fasting blood samples were taken to measure 25(OH)D level by electrochemiluminescence immunoassay. Multivariate linear regression was used to analyze the data.

\section{RESULTS}

The data showed that BMI, BF, and $\mathrm{WC}$ were higher than recommended, while SMM and serum $25(\mathrm{OH}) \mathrm{D}$ were lower. When the analysis was done based on sex, there were significant differences in BF, SMM, WHtR, and serum $25(\mathrm{OH}) \mathrm{D}$. In the linear regression multivariate analysis of $\log 25(\mathrm{OH}) \mathrm{D}$ with age and body anthropometric measurements, only SMM reached significance level $(\beta=0.019 ; \mathrm{p}=0.025)$.

\section{CONCLUSIONS}

This study demonstrated a positive association between skeletal muscle mass and serum levels of vitamin D in elderly.

Keywords : 25(OH)D, elderly, sex, anthropometric measurements 


\section{INTRODUCTION}

Vitamin D attracted much attention during the last years. The ideas about the importance of vitamin $\mathrm{D}$ and its connection with both communicable and non- communicable diseases have made many researchers interested to do various studies. Some of the diseases that have been linked to low vitamin D status are osteoporosis, cancer, the metabolic syndrome, and cardiovascular disease. ${ }^{(1)}$ Vitamin D deficiency is a highly prevalent condition, even in Indonesia, a tropical country with abundant sun exposure.

Vitamin D is a fat-soluble vitamin. There are two major forms of vitamin D, i.e. vitamin $\mathrm{D}_{2}$ and vitamin $\mathrm{D}_{3}$. Vitamin $\mathrm{D}_{2}$ (ergocalciferol) is found in plants and can be consumed as a supplement or in fortified foods. ${ }^{(1)}$ Vitamin $\mathrm{D}_{3}$ (cholecalciferol) is synthesized in the human epidermis or consumed in the form of natural or fortified food sources or as a supplement. ${ }^{(1)}$ Vitamin $\mathrm{D}$ in the form of $1,25(\mathrm{OH})_{2} \mathrm{D}$ is a hormone and the active form of vitamin $\mathrm{D}$. Directly or indirectly $1,25(\mathrm{OH})_{2} \mathrm{D}$ regulates over 200 genes, including those involved in renin production in the kidney, insulin production in the pancreas, release of cytokines from lymphocytes, production of cathelicidin in macrophages, induction of terminal differentiation, and growth and proliferation of both vascular smooth muscle cells and cardiomyocytes. ${ }^{(1,2)}$

Individual vitamin D status can be estimated by measuring plasma 25 -hydroxy vitamin D levels [abbreviated to $25(\mathrm{OH}) \mathrm{D}]$. Most experts define vitamin D deficiency as a $25(\mathrm{OH})$ D level of $<20 \mathrm{ng} / \mathrm{mL}$ ( $50 \mathrm{nmol} / \mathrm{l})$, vitamin $\mathrm{D}$ insufficiency as $21-29 \mathrm{ng} / \mathrm{mL}(525-725 \mathrm{nmol} /$ 1) and optimal concentration of vitamin $D$ as at least $30 \mathrm{ng} / \mathrm{mL}){ }^{(2)}$ Vitamin D deficiency may be due to inadequate dietary intake, inadequate exposure to sunlight, or malabsorption.

During aging, body composition changes, leading to increased adiposity and decreased skeletal muscle mass (SMM). ${ }^{(3)}$ Obesity, defined as excessive fat accumulation, is associated with low 25(OH)D. Low levels of vitamin D in obesity has been suggested as due to sequestration in fat, increased clearance by a larger body-fat pool, and decreased sun exposure. ${ }^{(4)}$

Several cross-sectional studies have investigated the relation between vitamin $\mathrm{D}$ to body mass index (BMI) dan body fat (BF), and those findings were inconsistent. Han et al. ${ }^{(5)}$ showed that there was a significant negative association between BF in adult men and women, but BMI and waist circumference (WC) were not significant in men. A meta-analysis showed a significant inverse weak correlation between serum vitamin D and BMI in the adult population, except for women living in developing countries. ${ }^{(6)}$ A recent meta-analysis concluded that vitamin D deficiency is associated with obesity irrespective of age, latitude, cut-offs to define vitamin D deficiency and the Human Development Index of the study location. ${ }^{(7)}$ Regarding the muscle mass, a study on subjects younger than 65 years showed that there was a statistically significant association between low $1,25(\mathrm{OH}) \mathrm{D}_{2}$ levels and low muscle mass both in men and women. ${ }^{(8)}$ A study on elderly concluded that lower $25(\mathrm{OH}) \mathrm{D}$ increased the risk of sarcopenia in older men and women. ${ }^{(9)}$

The elderly have a strong need to maintain normal vitamin D status. It has been estimated that $20-100 \%$ of elderly men and women are vitamin $D$ deficient. ${ }^{(2)}$ Considering the importance of vitamin $\mathrm{D}$ and obesity in general health and the tendency to vitamin D deficiency in the elderly, this study's objective was to determine the relationship between vitamin D and anthropometric measurements in the elderly population.

\section{METHODS}

\section{Research design}

This cross-sectional study was conducted in the Pusat Santunan Dalam Keluarga (PUSAKA) non-institutional elderly care centers II, $\mathrm{V}$ and $\mathrm{X}$ in Central Jakarta between JanuaryMarch 2016. 


\section{Research subjects}

Subjects were men or women $>60$ years old and willing to participate in the study. Exclusion criteria were: being bedridden, on dialysis and having consumed vitamin D supplements for the last 3 months. The number of subjects needed in the current study was 126 , on the basis of $r=0.455$, with $\mu=0.05$ and power $=90 \%{ }^{(10)}$ The study subjects were selected by simple random sampling from a total of 245 elderly. Written informed consent was obtained from each subject.

\section{Anthropometric measurements}

The collected data included subject characteristics, such as age, sex, and history of family illness. Height was measured using a stadiometer or as sitting knee height. Body weight (BW), BF, and SMM percentage was assessed by means of bioelectrical impedance analysis (BIA) using the body composition monitor with scales (HBF-375, Omron, Japan). Body mass index was calculated as weight $(\mathrm{kg})$ divided by height (m) squared. Waist circumference was measured with a non-stretch tape with a precision of one millimeter. The measurement was made at the level of the umbilicus, with the subject in the erect position, breathing silently. Waist-toheight ratio (WHtR) was calculated by dividing waist circumference by height in centimeters.

\section{Serum 25(OH)D measurement}

The serum level of $25(\mathrm{OH}) \mathrm{D}$ is a good indicator of vitamin $\mathrm{D}$, because it has a slower clearance than $1,25(\mathrm{OH})_{2}$ D. ${ }^{(11,12)}$ Venous blood samples of $5 \mathrm{~mL}$ were obtained in the morning after an overnight fast. Blood was collected in evacuated tubes and stored at $2-8^{\circ} \mathrm{C}$ and transported to the designated laboratory. Serum 25(OH)D levels were determined using direct competitive chemoluminescent immunoassay (CLIA) (DiaSorin, Stillwater, MN). This assay can detect levels ranging from 4.0 to $150 \mathrm{ng} /$ $\mathrm{mL}$, based on $3.90 \% \mathrm{CV}$ inter-assay precision. ${ }^{(13)}$ The examination for serum $25(\mathrm{OH}) \mathrm{D}$ was done simultaneously at one point in time.

\section{Statistical analysis}

We performed a sex-stratified analysis. The Kolmogorov-Smirnov normality test was used to assess the normality of distribution of all data. The differences between mean values for each tested variable between man and women were tested by independent Student $t$ test or Mann-Whitney test.

Multivariate linear regression analysis was used to evaluate associations between anthropometric measurements and serum $25(\mathrm{OH}) \mathrm{D}$. A p-value of $<0.05$ was considered statistically significant.

\section{Ethical clearance}

Ethical clearance No. 77/KER/FK/V/2015 was obtained from the Ethics Committee for Medical Research, Faculty of Medicine, Trisakti University, prior to the study.

\section{RESULTS}

Most of the subjects were women (86.5\% vs. $13.5 \%$ ). Mean BMI was categorized as obese. Mean WC was high for women but within a normal range for men. Mean WHtR was still in the normal category for people older than 60 years. The median of BF was high for men but in the normal range for women. Median 25(OH)D concentration of all subjects indicated vitamin $\mathrm{D}$ deficiency (Table 1). Based on serum 25(OH)D, there were $80.2 \%$ subjects who had vitamin D

Table 1. Characteristics distribution of all subjects $(\mathrm{n}=126)$

\begin{tabular}{lc}
\hline Variable & \\
\hline Sex & $17(13.5 \%)$ \\
$\quad$ Men & $109(86.5 \%)$ \\
Women & $70.07 \pm 6.39$ \\
Age (years) & $23.41 \pm 5.10$ \\
Body Mass Index (kg/m $\left.{ }^{2}\right)$ & $33.83 \pm 7.54$ \\
Body fat (\%) & $21.72 \pm 3.48$ \\
Skeletal muscle mass (\%) & $81.22 \pm 1.75$ \\
Waist circumference (cm) & $0.55 \pm 0.08$ \\
Waist-to-height ratio (WHtR) & $13.9(4.0-59.3)$ \\
25(OH)D (ng/dL) & \\
*Data presented as mean $\pm \mathrm{SD}$, except for 25(OH)D level \\
as median (min.-max.)
\end{tabular}


Table 2. Characteristics of subjects based on sex

\begin{tabular}{lccc}
\hline \multicolumn{1}{c}{ Variable } & Men $(\mathbf{n}=\mathbf{1 7})$ & Women $(\mathbf{n}=109)$ & p value \\
\hline Age (years) & $69.71 \pm 7.50$ & $70.15 \pm 6.29$ & 0.612 \\
Body Mass Index $\left(\mathrm{kg} / \mathrm{m}^{2)}\right.$ & $22.29 \pm 4.88$ & $23.57 \pm 5.17$ & 0.333 \\
Body fat (\%) & $24.17 \pm 6.28$ & $35.30 \pm 6.60$ & $0.0001^{*}$ \\
Skeletal muscle mass (\%) & $27.39 \pm 2.82$ & $20.84 \pm 2.66$ & $0.0001^{*}$ \\
Waist circumference (cm) & $81.52 \pm 13.48$ & $81.18 \pm 11.63$ & 0.911 \\
Waist-to-height ratio (WHtR) & $0.51 \pm 0.08$ & $0.55 \pm 0.07$ & $0.043^{*}$ \\
25(OH)D (ng/dL) & $16.9(12.4-59.3)$ & $13.4(4.7-30.1)$ & $0.004^{* *}$ \\
\hline
\end{tabular}

${ }^{*} \mathrm{p}<0.05$ t-test; ** $\mathrm{p}<0.05$ Mann-Whitney; Data presented as mean $\pm \mathrm{SD}$, except for 25(OH)D level as median (min.-max.)

deficiency, $15.9 \%$ vitamin D insufficiency and only $4 \%$ reached a sufficient level of vitamin $D$.

When an analysis was done by sex, there were significant differences in body fat, skeletal muscle mass, WHtR, and serum 25(OH)D, while the other variables were not significantly different (Table 2).

In the multivariate linear regression analysis between $\log 25(\mathrm{OH}) \mathrm{D}$ and all variables, only SMM correlated significantly with serum level of $\log 25(\mathrm{OH}) \mathrm{D}$. (Table 3$)$. High skeletal muscle mass was associated with increased serum level of $\log 25(\mathrm{OH}) \mathrm{D}(\beta=0.019 ; \mathrm{p}=0.025)$.

\section{DISCUSSION}

Our study showed that there was a significant difference in BF percentage between men and women. This result agrees with one other study which showed that women have a higher fat tissue percentage (73.6\%) compared to men $(16.5 \%) .{ }^{(14)}$ Mean BMI in our study was categorized as obese grade 1 according to the classification for obesity in the Asia-Pacific population. ${ }^{(15)}$
A study in Mexico on 1,968 subjects older than 60 years showed that $62.3 \%$ of the subjects were obese. ${ }^{(14)}$ In Indonesia, the prevalence of overweight is higher in women (22.9\%) compared with men $(16.0 \%){ }^{(16)}$ Aging is related to changes in body composition, usually marked by a decrease in fat-free mass (FFM) and an increase in body fat mass (BFM).

The WC in our study was $81.22 \pm 11.75$ $\mathrm{cm}$. The simplest method to examine excess abdominal fat (central body fat) is WC, because it correlates with abdominal fat mass (subcutaneous and intra-abdominal). The WHtR is a very simple, low-cost anthropometric measurement as an indicator of early health risk if the WHtR is $>0.5$ for the age group between 40-50 years, while the critical value for people over 50 years is $>0.6 .^{(17-19)}$ The WHtR in our study was borderline, between 0.5 and 0.6 , so that we can conclude that there is an increased health risk. The SMM was significantly different between men and women. This was in line with the theory that there is sexual dimorphism of SMM, with higher SMM in men. The recommended level of serum $25(\mathrm{OH}) \mathrm{D}$ is higher

Table 3. Multivariate linear regression analysis between the log-transformed 25(OH)D and other parameters

\begin{tabular}{lccc}
\hline \multirow{2}{*}{ Variable } & \multicolumn{2}{c}{$\log \mathbf{2 5}(\mathbf{O H}) \mathbf{D}$} & \multirow{2}{*}{ p value } \\
\cline { 2 - 3 } & $\boldsymbol{\beta}$ & Beta & 0.619 \\
Age (years) & 0.001 & 0.048 & 0.541 \\
Body Mass Index $\left(\mathrm{kg} / \mathrm{m}^{2)}\right.$ & 0.005 & 0.146 & 0.745 \\
Body fat $(\%)$ & -0.001 & -0.047 & $0.025^{*}$ \\
Skeletal muscle mass (\%) & 0.019 & 0.344 & 0.801 \\
Waist circumference (cm) & -0.001 & -0.087 & 0.785 \\
Waist-to-height ratio (WHtR) & -0.232 & -0.099 & \\
\hline
\end{tabular}

${ }^{*} \mathrm{p}<0.05 ; \beta$ : regression coefficient; Beta: standardized regression coefficient 
for people living in tropical countries. Unfortunately, a high prevalence of vitamin D deficiency is also reported in tropical countries, including Indonesia. ${ }^{(20)}$ Our study showed very low serum vitamin D levels in the elderly. A previous study in Indonesia showed the same result, i.e. that there is a high prevalence of vitamin $\mathrm{D}$ deficiency in the elderly. ${ }^{(21)} \mathrm{An}$ increase in $24(\mathrm{OH})$ ase gene expression and in $1,25(\mathrm{OH})_{2} \mathrm{D}_{3}$ clearance with age has been reported. The study of Angel et al. ${ }^{(22)}$ showed an increase in the proportion of vitamin D deficiency in older age, especially in women.

Serum 25(OH)D was significantly different between men and women in our study, where women were found to be at higher risk of vitamin D deficiency. The study by Huang et al. (23) showed that in the elderly, the female gender is a risk factor for low vitamin D status. The sex difference in correlation with vitamin $\mathrm{D}$ was also found in other studies. ${ }^{(24-26)}$ The low serum level of $25(\mathrm{OH}) \mathrm{D}$ in our study might have been influenced by the great number of female participants. This may be explained by the observation that women generally prefer indoor activities and take more precautions against sunlight exposure. Avoidance of sunlight exposure was found to be the reason for the low serum $25(\mathrm{OH}) \mathrm{D}$, especially in women. Moreover, most of the women in this study wear the hijab (headscarf) which will reduce sun exposure of the skin. To the best of our knowledge, no studies have examined the correlation between vitamin D level and WHtR. Although in our study the correlation between WHtR was not statistically significant, it could be considered for further exploration.

The multivariate linear analysis in our study showed that high skeletal muscle mass was significantly associated with increased serum 25(OH)D level. The study of Ko et al. ${ }^{(25)}$ showed similar results, in that there might be a positive relationship between 25(OH)D and SMM. On the contrary, Meng at al. ${ }^{(27)}$ found no significant association between $25(\mathrm{OH}) \mathrm{D}$ and appendicular SMM in elderly.
Other parameters in our study showed no significant association with $\log 25(\mathrm{OH}) \mathrm{D}$. A linear regression analysis conducted by Han et al. ${ }^{(5)}$ also showed no association between BMI and $\mathrm{WC}$, although $\mathrm{BF}$ was inversely associated with serum $25(\mathrm{OH}) \mathrm{D}$. Aging is related to changes in body composition, usually marked by a decrease in fat-free mass (FFM) and an increase in body fat mass (BFM). BMI may reasonably predict adverse outcomes in global population-based adult studies, but recent studies have demonstrated that BMI cutoffs may misrepresent the degree of adverse outcomes in the older population. ${ }^{(28,29)}$ That is why, in older adults, BMI may be a suboptimal marker for adiposity.

This study used Bioimpedance Analysis (BIA) to assess body fat. BIA is less accurate in older adults and can be influenced by food consumption, exercise, ethnicity, and certain medical conditions. A limitation of the present study is that food intake of the subjects was not assessed because nearly all of the subjects have the same meal pattern as part of PUSAKA policies. The use of WHtR as a tool to assess visceral fat could be considered besides WC and BMI. Most of the studies used BMI or WC to analyze obesity or fat content, a smaller number used BF analysis and only very few of the published studies used WHtR. Another limitation of the present study is the lack of data on physical activity.

In the elderly, the tendency to vitamin D deficiency is relatively high, so that they should be advised to increase serum 25(OH)D by more direct sunlight exposure and higher intake of food sources of vitamin D. It is recommended that Indonesians should have sunlight exposure for 25 minutes at 09.00 , or 15 minutes at 09.00 10.00 to have a vitamin D concentration of 2700 IU in the blood for each exposure, and minimally $3 \mathrm{x} /$ week to prevent the development of vitamin D deficiency. ${ }^{(26)}$

The elderly should be advised to maintain their level of SMM by consuming a moderate amount (25-30 g) of high-quality protein and do 
resistance exercises. ${ }^{(30)}$ It is suggested that the elderly also maintain a normal body weight so that their BMI, WC, BF, WHtR remain in the normal range. This can be done by showing healthy food models to the elderly and the PUSAKA policymakers. Supplementation of either vitamin D2 or vitamin D3 can be used to treat and prevent vitamin D deficiency.

\section{CONCLUSIONS}

Our study demonstrated that high skeletal muscle mass is associated with increased serum levels of vitamin $D$ in the elderly. Further studies of prospective design are needed to examine whether vitamin $D$ supplementation has beneficial effects on muscle mass among the elderly.

\section{CONFLICT OF INTEREST}

Competing interests: No relevant disclosures. The authors declare no conflict of interest in relation to this article.

\section{ACKNOWLEDGEMENT}

The authors wish to thank Dr. dr. Rina K Kusumaratna, M.Kes. for advice and suggestions in the successful completion of this study.

\section{CONTRIBUTORS}

VS originated the idea for this study, did the research proposal, data analysis and prepared the manuscript. LH contributed to the research proposal, reviewed the analysis and participated in the manuscript preparation. VS and LH conducted the data analysis and revised the manuscript. Both authors read and approved the final version.

\section{REFERENCES}

1. Holick MF. Vitamin D deficiency. N Engl J Med 2007;357:266-81.
2. Holick MF, Binkley NC, Bischoff-Ferrari HA, et al. Evaluation, treatment, and prevention of vitamin D deficiency: an Endocrine Society Clinical Practice Guideline. J Clin Endocrinol Metab 2011;96:1911-30.

3. Batsis JA, Mackenzie TA, Bartels SJ, et al. Diagnostic accuracy of body mass index to identify obesity in older adults: NHANES 19992004. Int J Obes 2016;40:761-7.

4. Kull M, Kallikorm R, Lember M. Body mass index determines sunbathing habits: implications on vitamin D levels. Intern Med J 2009;39:256-8.

5. Han SS, Kim M, Lee SMM, et al. Association between body fat and vitamin D status in Korean adults. Asia Pac J Clin Nutr 2014;23:65-75.

6. Saneei P, Salehi-Abargouei A, Esmaillzadeh A. Serum 25-hydroxyvitamin $D$ levels in relation to body mass index: a systemic review and metaanalysis. Obes Rev 2013;14:393-404.

7. Pereira-Santos M, Costa PRF, Assis AMO, et al. Obesity and vitamin D deficiency: a systemic review and meta-analysis. Obes Rev 2015;16:341-9.

8. Marantes I, Achenbach SJ, Atkinson EJ, et al. Is vitamin $\mathrm{D}$ a determinant of muscle mass and strength? JBMR 2011;26:2860-71.

9. Visser M, Deeg DJH, Lips P. Low vitamin D and high parathyroid hormone levels as determinants of loss of muscle strength and muscle mass (sarcopenia): the Longitudinal Aging Study Amsterdam. J Clin Endocrinol Metab 2008;88: 5766-72.

10. Kuwabara A, Tsugawa N, Kondo H, et al. Associations between serum 25-hydroxyvitamin D3 level and skeletal muscle mass and lower limb muscle strength in Japanese middle-aged subjects. Osteoporosis Sarcopenia 2017;3:53-8.

11. Palomer X, González-Clemente JM, Blanco-Vaca $F$, et al. Role of vitamin $D$ in the pathogenesis of type 2 diabetes mellitus. Diab Obes Metabol 2008: 10:185-97.

12. Wimalawansa SJ. Vitamin D in the new millennium. Curr Osteoporosis Rep 2012;10:4-15.

13. Sari DK, Al Rasyid H, Lipoeto NI, et al. Are avoiding sunlight exposure and low physical activity resulting micro evolution in tropical country women? SCIRJ 2013;1:18-26.

14. Sánchez-García S, García-Peña C, Duque-López MX, et al. Anthropometric measures and nutritional status in a healthy elderly population. BMC Public Health 2007;7:2. doi: 10.1186/14712458-7-2.

15. WHO Expert Consultation. Appropriate bodymass index for Asian populations and its implications for policy and intervention strategies. Lancet 2004;363:157-63. 
16. Sari K, Mansyur M. Female, live in urban, and the existence of a caregiver increased risk overnutrition in elderly: an Indonesian national study 2010. Health Sci Indones 2012;3:9e14.

17. Schneider HJ, Friedrich N, Klotsche J, et al. The predictive value of different measures of obesity for incident cardiovascular events and mortality. J Clin Endocrinol Metab 2010;95:1777-85.

18. Lee CM, Huxley RR, Wildman RP, et al. Indices of abdominal obesity are better discriminators of cardiovascular risk factors than BMI: a metaanalysis. J Clin Epidemiol 2008;61:646-53.

19. Browning LM, Hsieh SD, Ashwell A. Systematic review of waist-to-height ratio as a screening tool for the prediction of cardiovascular disease and diabetes: 0.5 could be a suitable global boundary value. Nutr Res Rev 2010;23:247-69.

20. Handono K, Ranuwijaya LK, Fitri LE, et al. The correlation between serum concentration of vitamin $\mathrm{D}$ with vitamin $\mathrm{D}$ receptor expression and disease activity in Indonesian patients with systemic lupus erythematosus: a preliminary study. Trop Life Sci Res 2014;4:113-8.

21. Hidayat R, Setiati S, Soewondo P. The association between vitamin $\mathrm{D}$ deficiency and type 2 diabetes mellitus in elderly patients. Acta Med Indones 2010;42:123-9.

22. Angel B, Sanchez H, Lera L, et al. Vitamin D deficiency/insufficiency and obesity and metabolic disorders in community-living Chilean elderly people. JARCP 2013;2:251-6.

23. Huang C, Huang YA, Lai Y, et al. Prevalence and predictors of hypovitaminosis D among the elderly in subtropical region. PLoS ONE 12 e0181063. DOI: https://oi.org/10.1371/journal. pone. 0181063.

24. Lim JS, Kim KM, Rhee Y, et al. Gender-dependent skeletal muscle effects of vitamin D deficiency in a younger generation. J Clin Endocrinol Metab 2012;97:1995-2004. doi: 10.1210/jc.2011-3098.

25. Ko MJ, Yun S, Oh K, et al. Relation of serum 25 hydroxyvitamin D status with skeletal muscle mass by sex and age group among Korean adults. Br J Nutr 2015;114:1838-44.

26. Setiati S, Oemardi M, Sutrisna B. The role of ultraviolet $\mathrm{B}$ from sun exposure on vitamin $\mathrm{D}$ and parathyroid hormone level in elderly women in Indonesia. Asian J Gerontol Geriatr 2007;2:12632.

27. Meng L, Man Q, Yuan L, et al. Serum 25 hydroxyvitamin D and elderly skeletal muscle mass and function in urban north China. Asia Pac J Clin Nutr 2017;26:849-55.

28. Batsis JA, Sahakyan KR, Rodriguez-Escudero JP, et al. Normal weight obesity and mortality in United States subjects $\geq 60$ years of age (from the Third National Health and Nutrition Examination Survey). Am J Cardiol 2013;112:1592-8.

29. Batsis JA, Singh S, Lopez-Jimenez F. Anthropometric measurements and survival in older Americans: results from the third National Health and Nutrition Examination Survey. J Nutr Health Aging 2014;18:123-30.

30. English KL, Paddon-Jones D. Protecting muscle mass and function in older adults during bed rest. Curr Opin Clin Nutr Metab Care 2010;13:34-9. 